\title{
Climate change impacts on health and wellbeing in rural and remote regions across Canada: a synthesis of the literature
}

\author{
Amy Kipp, MA (1); Ashlee Cunsolo, PhD (2); Kelly Vodden, PhD (3); Nia King, BSc (4); Sean Manners, BA (3); \\ Sherilee L. Harper, PhD (1)
}

Tweet this article

\begin{abstract}
This article provides a synthesis of the forthcoming first order draft of the Canadian Government's National Assessment on Climate Change 'Rural and Remote' chapter, highlighting key health concerns from the literature associated with climate change in rural and remote regions, as well as existing and future adaptation strategies. To support the health and wellbeing of those experiencing the negative effects of climate change, and utilizing systematic search processes, this synthesis article highlights the importance of considering the specific socio-cultural, economic, and geographic elements and existing expertise of individuals and communities in rural and remote regions.
\end{abstract}

Keywords: climate change, health, wellbeing, rural, remote, adaptation, Canada

\section{Introduction}

In rural and remote regions (see Box 1) across Canada, human health and wellbeing are often influenced by the close connection individuals and communities have to their social, cultural, and physical environments. ${ }^{1-5}$ These communities often rely closely on the environment for their sustenance, livelihoods, and cultural practices, influencing the social determinants of health and wellbeing. ${ }^{1-3,5,6}$ As a result, climate change is directly and indirectly impacting the health and wellbeing of individuals and communities. ${ }^{1,2,5,7,8}$

This article synthesizes the health content from the first order draft of the 'Rural and Remote' chapter of the Canadian government's forthcoming National Assessment on Climate Change, Canada in a Changing
Climate: Advancing Our Knowledge for Action. ${ }^{9}$ The Rural and Remote Chapter is one of several national issues chapters of The National Assessment, including chapters focused on Our Natural Capital, International Dimensions, and Resilience of Our People and Society, for example, as well as regional chapters, such as Northern Canada, British Columbia, the Prairies, Ontario, Quebec, and Atlantic Canada.* This assessment will serve as an important resource for communities, policy-makers, and academics to support climate change adaptation decisions and actions and explores how Canada's climate is changing, the impacts of these changes on Canadians, and the adaptation strategies being used to reduce climate related risks. ${ }^{9}$ The Rural and Remote Chapter, and by extension this article, is
Highlights

- Climate change negatively impacts the health and wellbeing of individuals and communities in rural and remote regions in Canada.

- Key health concerns from the National Assessment on Climate Change 'Rural and Remote' include the exacerbation of issues associated with food and water security, chronic illness, infectious disease, unintentional injury and death, and mental health.

- Although specific characteristics increase climate change vulnerability of rural and remote regions, many strengths within these regions support resilience to climate change.

- Focusing on climate change adaptation, as well as realizing co-benefits from climate change mitigation, presents important opportunities for the health sector.

based on a scoping review of gray and peer-reviewed literature; ongoing engagement with researchers, governments, communities, organizations, and Indigenous knowledge-keepers and leaders; and collaboration with other Chapters in the National Assessment. The scoping review characterized the nature, range, and extent

\footnotetext{
${ }^{*}$ For a complete list of Chapters and more information on the National Assessment on Climate Change visit: https://www.nrcan.gc.ca/environment/impacts-adaptation/19926

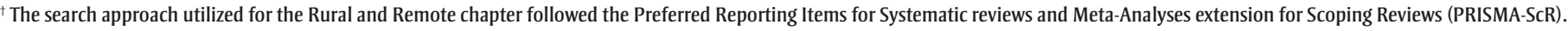

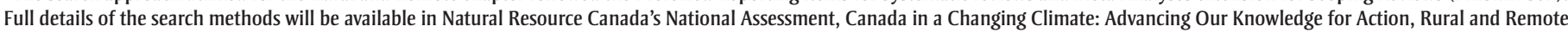
Chapter (forthcoming 2020).
} 
BOX 1

Definition of rural and remote regions

Building from the PHAC definition, ${ }^{31}$ rural and remote regions are defined as areas with less than 10000 people, in which rural regions have less than $50 \%$ of the population that commute to an urban location for work, and remote communities have no residents that commute to an urban location for work or the community is located in one of the Canadian territories.

of literature on climate change impacts and adaptation in rural and remote Canadian communities, and included literature published since the last national assessment (2013). Based on quantitative and qualitative analysis of the scoping review, as well as input from engagement and collaboration, key health concerns associated with climate change and adaptation strategies in rural and remote regions throughout Canada were identified. This article provides a brief overview of these key health concerns.

\section{Climate change, health, and wellbeing in rural and remote regions}

Many changing climate conditions and resultant environmental impacts negatively affect individual and community health and wellbeing in rural and remote regions, including: increased prevalence and severity of extreme weather events; ;,2,5,10-12 changes to sea ice, vegetation, fish, wildlife, and water; ${ }^{1,2,5,12,13}$ and weather and environmental uncertainties. ${ }^{1,2,6,14}$

Negative health outcomes associated with these changes include an increased prevalence of poor nutrition, obesity, and diabetes; $5,15,16$ vector-borne, waterborne, and foodborne disease; ;,12,16,17 cardiovascular disease $;{ }^{15,16}$ respiratory issues $;^{18}$ injury and mortality; ${ }^{12-14}$ and mental health issues. , $^{3,6,18-20}$ Characteristics of rural and remote regions may increase the sensitivity to these health risks, such as remote geography and limited transportation infrastructure, reliance on natural resources, and underresourced social and physical infrastructure. ${ }^{2,5}$ Additionally, vulnerability to climate change is influenced by the intersection of social, cultural, and political factors in rural and remote regions as well as individual characteristics and circumstances., ${ }^{2,5,21,22}$ Based on a synthesis of the literature from this scoping review, key health concerns in rural and remote areas include: 1) challenges with access to and quality of food and water; 2) exacerbation of chronic illness and infectious disease; 3) potential unintentional injury and death; and 4) intensified challenges with mental health and wellbeing. Furthermore, the literature highlights Indigeneity, age, gender, and socioeconomic status as key factors influencing individual and community vulnerability to climate change in rural and remote regions.

\section{Changing access and availability of nourishing, accessible, and preferred food and water}

Many rural and remote regions have experienced changing access to, and quality of, food and water systems, linked to environmental changes such as rising temperatures, ${ }^{7,16,20,23}$ changing precipitation patterns, and increasing incidents of extreme weather events. ${ }^{7,18,23}$ For example, in many Northern remote First Nations and Inuit communities, climate-changerelated disruptions to sea ice, wildlife, and vegetation impacts the ability of individuals to hunt, fish, and forage, leading to decreased consumption of healthy and culturally-preferred local food and increased reliance on retail food.7,16,18,19,23 Water security, including access, availability and quality, may also be challenging in rural and remote regions, where rising temperatures and more frequent extreme weather events can overwhelm fragile water treatment systems, interrupting the provision of safe drinking water. ${ }^{7,23}$ Across Northern Canada, where many communities rely on surface water sources, changes to water levels, run-off, flow regimes, and sediment accumulation can drastically affect

TABLE 1

Examples of existing and potential adaptation strategies to the negative health effects of climate change in rural and remote communities in Canada

\begin{tabular}{|c|c|}
\hline Examples of existing adaptation strategies & References \\
\hline Introducing local food production systems & $15,16,19$ \\
\hline $\begin{array}{l}\text { Using experience-based knowledge of local communities to support } \\
\text { community resilience }\end{array}$ & $3,6,12$ \\
\hline $\begin{array}{l}\text { Developing community-based monitoring programs and research to gather data } \\
\text { about environment and health to inform decision making }\end{array}$ & $5-7,18,25$ \\
\hline $\begin{array}{l}\text { Using Indigenous Knowledge and Local Knowledge regarding the physical } \\
\text { environment, to support hazard avoidance and emergency preparedness }\end{array}$ & $12-14$ \\
\hline $\begin{array}{l}\text { Utilizing a social development approach, which involves health professionals, } \\
\text { social workers, and those in caring professions supporting those directly impacted } \\
\text { by climate change to strengthen community capacity }\end{array}$ & 22 \\
\hline $\begin{array}{l}\text { Fostering protective factors for physical and mental health through connection to } \\
\text { land-based activities, cultural arts and crafts, and opportunities for bringing } \\
\text { community together }\end{array}$ & 27 \\
\hline Examples of potential adaptation strategies & References \\
\hline $\begin{array}{l}\text { Using local knowledge, Indigenous Knowledge, and/or western knowledge to } \\
\text { respond to specific local sociocultural contexts }\end{array}$ & $7,12,19,22$ \\
\hline $\begin{array}{l}\text { Eliminating social barriers to adaptation (e.g. poverty, inequality, housing } \\
\text { concerns, etc.) and reducing non-climatic factors (e.g. chronic disease) }\end{array}$ & 5,22 \\
\hline $\begin{array}{l}\text { Utilizing innovative forms of technology (e.g. telehealth, mobile monitoring } \\
\text { applications; satellite imagery) }\end{array}$ & 5,19 \\
\hline Improving public health surveillance and furthering monitoring programs & $5,7,8,12,14,15,23,24,29$ \\
\hline Supporting sustainable development practices (e.g. clean energy programs) & $12,19,22,29$ \\
\hline $\begin{array}{l}\text { Enhancing communication and awareness of risks and responses (e.g. lists of safe } \\
\text { spaces, pamphlets regarding disease outbreaks; developing outreach strategy) }\end{array}$ & $5,12,18,19,29$ \\
\hline $\begin{array}{l}\text { Expanding knowledge of climate change impacts on health through research and } \\
\text { investment, and sharing best practices for public health adaptation }\end{array}$ & $5,19,29$ \\
\hline $\begin{array}{l}\text { Developing the capacity of health systems and emergency response to withstand } \\
\text { and respond to climate risks (e.g. creating technical guidance and training courses; } \\
\text { integrating climate change into medical and public health training) }\end{array}$ & 14,19 \\
\hline
\end{tabular}


drinking water availability and quality. ${ }^{23,24}$ Both food and water insecurity have been linked to negative health outcomes, including poor nutrition, obesity, diabetes, cardiovascular disease, acute gastrointestinal illness, and mental health concerns. ${ }^{7,12,16,25}$

\section{Exacerbation of chronic illness and infectious disease}

Changing precipitation patterns, rising temperatures, and increased frequency and severity of extreme weather conditions can also exacerbate chronic illnesses and infectious diseases in rural and remote regions by increasing exposure to environmental contaminants, and vectorborne, foodborne, and waterborne diseases; ${ }^{16}$ putting enhanced stress on underlying chronic conditions (e.g. cardiovascular and respiratory illness);,418 and disrupting healthcare provision and chronic disease management. ${ }^{6}$ Further, research has documented increased risk of waterborne disease in rural and remote areas, due to weather-related contamination events. ${ }^{5,25}$ Additionally, changing winds, ocean currents, and rivers, carrying environmental contaminants North, may lead to increased levels of persistent organic pollutants and toxic heavy metals in local food and water sources in remote polar regions; $;^{7,16,23}$ the consumption of contaminants can result in many health concerns. ${ }^{7}$

\section{Changing climate conditions resulting in increased injury and mortality}

Extreme and rapidly changing weather conditions, including heat waves, storms, droughts, flooding, and changing sea ice conditions, have had significant negative effects on the health of individuals in rural and remote regions. For example, an increase in the number of heat waves experienced in rural regions was associated with increased heat stroke and respiratory related emergency room visits. ${ }^{26}$ Additionally, wild fires and associated health challenges, such as respiratory issues, mental health stressors, and damage to critical health infrastructure, have been identified in forest communities across Canada as a threat to safety and wellbeing. ${ }^{11,18,19}$

\section{Changing and uncertain environmental conditions impacting mental health and wellbeing}

As environments change and people adapt to new and often fewer desirable conditions, the mental health and wellbeing of individuals in rural and remote regions is also affected. For example, in Indigenous communities in rural and remote regions of Canada, individuals are often deeply connected to the land for their wellbeing; as climatic changes alter the environment, access to places and practices of cultural significance are often disrupted. ${ }^{3,6,12,27}$ For Nunatsiavut Inuit, for example, these changes have led to increased anxiety, fear, distress, anger, grief, and depression related to changes to land-based activities, connection to land, and cultural identity. ${ }^{3,25,27}$

FIGURE 1

Visual summary of key health challenges and adaptation strategies in the context of climate change in rural and remote regions in Canada

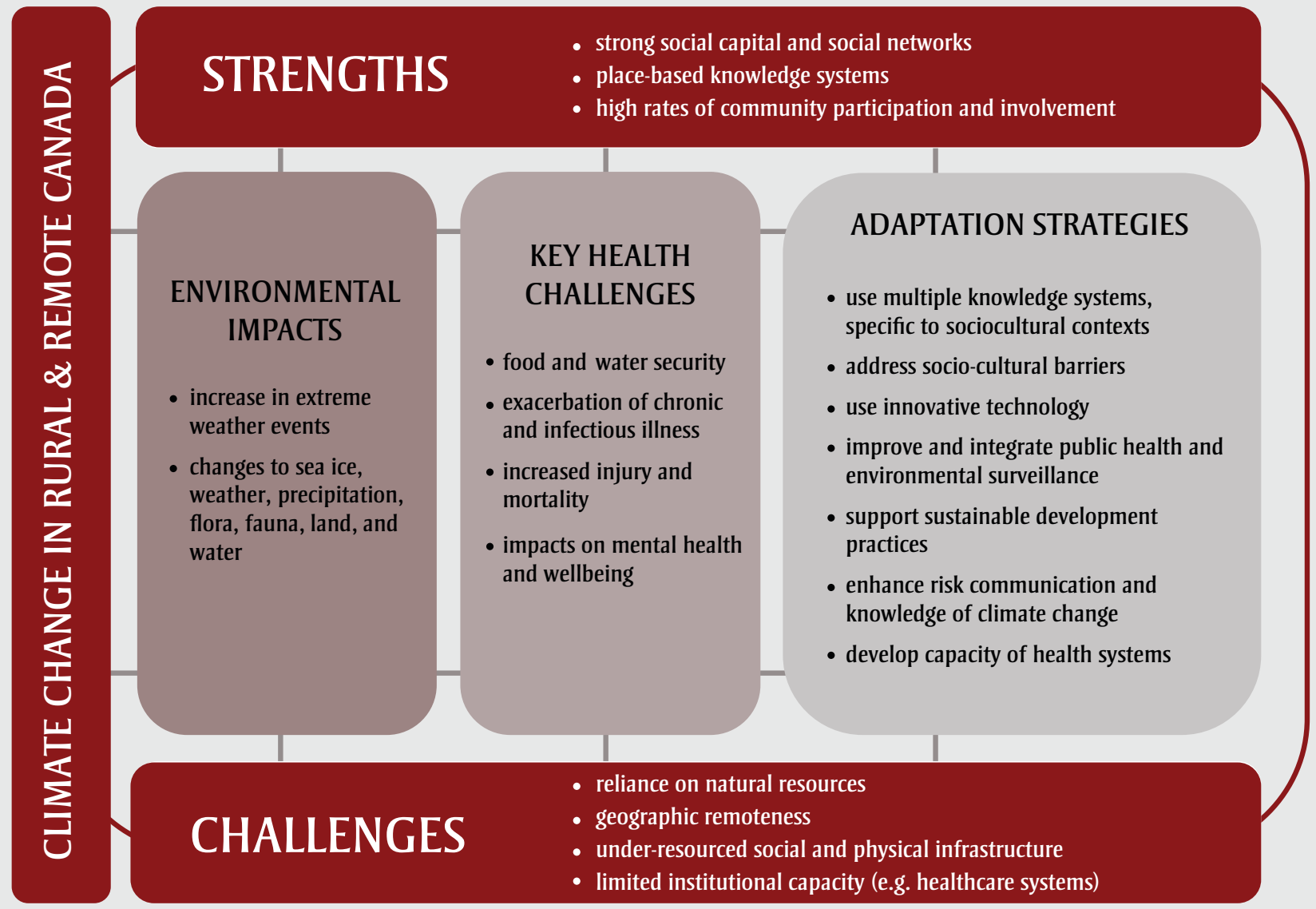


In regional plans in Manitoba, the potential loss of livelihoods associated with drought was identified as a climate-sensitive mental health concern. ${ }^{28}$ In Atlantic Canada, individuals have connected an increase in the prevalence and severity of storms in rural coastal communities and the subsequent damage to important mental health infrastructure, ${ }^{29}$ which often differs by gender. ${ }^{30}$

\section{Climate change adaptation responses and opportunities in rural and remote regions}

Despite these challenges, focusing on climate change adaptation, as well as realizing co-benefits from climate change mitigation, presents an important opportunity for the health sector. Already many Canadian rural and remote communities have begun to develop and implement health-related adaptation strategies (Table 1). To support adaptation to the health effects of climate change, a number of changes to existing adaptation strategies are needed, including: using multiple knowledge systems, specific to sociocultural contexts; addressing non-climatic factors impacting adaptation; utilizing innovative forms of technology; improving and integrating health surveillance with environmental monitoring; supporting sustainable development practices; enhancing awareness of risks and response; expanding knowledge of climate change impacts; and developing the capacity of the health sector to respond to climate change (Table 1). Ultimately, for rural and remote communities to continue to adapt to the health impacts of climate change, it is important to consider the specific local and regional socio-cultural, economic, and geographic elements; support and draw upon existing expertise of individuals and communities in rural and remote areas in Canada; and continue to view human health within the social-cultural and physical environments of rural and remote regions (Figure 1).

\section{Acknowledgements}

Thanks to Don Lemmen, Fiona Warren, and the managing team of the Natural Resources Canada (NRCan) National Assessment, Canada in a Changing Climate: Advancing Our Knowledge for Action, whose permission was obtained to publish this article. We would also like to thank the rural and remote communities, researchers, and policy-makers whose knowledge and expertise helped to inform the writing of this overview.

\section{Conflicts of interest}

The authors have no conflicts of interest to declare.

\section{Authors' contributions and statement}

AC, SLH, and KV contributed to conceptualizing the literature review and search string to identify peer-reviewed and gray literature. NK and SM conducted the literature review search and extracted quantitative information from articles. $\mathrm{AK}, \mathrm{AC}$, and SLH analyzed articles qualitatively and synthesized information, including identifying emergent themes related to health concerns and adaptation strategies, as well as drafted the article. All authors contributed to revising the article.

The content and views expressed in this article are those of the authors and do not necessarily reflect those of the Government of Canada.

\section{References}

1. Intergovernmental Panel on Climate Change. Climate Change 2014: Impacts, Adaptation, and Vulnerability. Part B: Regional Aspects. Contribution of Working Group II to the Fifth Assessment Report of the Intergovernmental Panel on Climate Change. In: Barros VR, Field CB, Dokke JD, et al., editors. Cambridge (UK), New York (USA): Cambridge University Press; 2014. $688 \mathrm{p}$.

2. Intergovernmental Panel on Climate Change. Climate Change 2014: Impacts, Adaptation, and Vulnerability. Part A: Global and Sectoral Aspects. Contribution of Working Group II to the Fifth Assessment Report of the Intergovernmental Panel on Climate Change. In: Field CB, Barros VR, Dokken DJ, et al., editors. Cambridge (UK), New York (USA): Cambridge University Press; 2014. 1132 p.

3. Cunsolo A, Ellis NR. Ecological grief as a mental health response to climate change-related loss. Nat Clim Chang. 2018;8(4):275-81. doi: 10.1038 /s41558-018-0092-2.
4. Public Health Agency of Canada. Climate change impacts on the health of Canadians [Internet]. Ottawa (ON): Public Health Agency of Canada; 2017. Available from: http://publications .gc.ca/collections/collection_2017 /aspc-phac/HP5-122-2017-eng.pdf

5. Expert Panel on Climate Change Adaptation and Resilience. Measuring progress on adaptation and climate resilience: recommendations to the Government of Canada [Internet]. Gatineau (QC): Environment and Climate Change Canada; 2018. 188 p. Available from: http://publications .gc.ca/collections/collection_2018 /eccc/En4-329-2018-eng.pdf

6. Cunsolo Willox A, Stephenson E, Allen J, et al. Examining relationships between climate change and mental health in the Circumpolar North. Reg Environ Chang. 2015;15(1):169-82.

7. Berner J, Brubaker $\mathrm{M}$, Revitch $\mathrm{B}$, Kreummel E, Tcheripanoff M, Bell J. Adaptation in Arctic circumpolar communities: food and water security in a changing climate. 2016;1:1-8.

8. Durkalec A, Furgal C, Skinner MW, Sheldon T. Climate change influences on environment as a determinant of Indigenous health: relationships to place, sea ice, and health in an Inuit community. Soc Sci Med. 2015;136-137: 17-26.

9. Natural Resources Canada. Canada in a Changing Climate [Internet]. Ottawa (ON): Natural Resources Canada; 2018 [cited 2018 Nov 26]. Available from: https://www.nrcan.gc.ca/environment /impacts-adaptation/19918

10. Rapaport E, Manuel P, Krawchenko T, Keefe J. How can aging communities adapt to coastal climate change? Planning for both social and place vulnerability. Can Public Policy. 2015; 41(2):166-77.

11. Government of Saskatchewan. Prairie resilience: a made-in-Saskatchewan climate change strategy [Internet]. Government of Saskatchewan; 2017. Available from: http://publications. gov.sk.ca/documents/66/104890-2017 Climate Change Strategy.pdf

12. Ford JD, Willox AC, Chatwood S, et al. Adapting to the effects of climate change on Inuit health. Am J Public Health. 2014;104(Suppl. 3):e9-17. 
13. Clark DG, Ford JD. Emergency response in a rapidly changing Arctic. Can Med Assoc J. 2017;189:e135-6.

14. Young SK, Tabish TB, Pollock NJ, Kue Young T. Backcountry travel emergencies in arctic Canada: a pilot study in public health surveillance. Int $\mathrm{J}$ Environ Res Public Health. 2016;13(3): 276.

15. Barbeau CD, Oelbermann M, Karagatzides JD, Tsuji LJS. Sustainable agriculture and climate change: producing potatoes (Solanum tuberosum L.) and bush beans (phaseolus vulgaris L.) for improved food security and resilience in a Canadian subarctic first nations community. Sustain. 2015; 7(5):5664-81.

16. Loring PA, Gerlach SC. Searching for progress on food security in the North American North: a research synthesis and meta-analysis of the peerreviewed literature. Arctic. 2015;68(3): 380-92.

17. Harper SL, Edge VL, Schuster-Wallace CJ, Berke O, McEwen SA. Weather, water quality and infectious gastrointestinal illness in two Inuit communities in Nunatsiavut, Canada: potential implications for climate change. Ecohealth. 2011;8(1):93-108.

18. Dodd W, Scott P, Howard C, et al. Lived experience of a record wildfire season in the Northwest Territories, Canada. Can J Public Heal. 2018; 109(3):327-37.

19. Government of Northwest Territories. Northwest Territories Climate Change Strategic Framework 2018-2030 [Internet]. Government of Northwest Territories; 2017. Available from: https:// www.enr.gov.nt.ca/sites/enr/files /resources/128-climate_change_strategic _framework_web.pdf

20. Statham S, Ford J, Berrang-Ford L, Lardeau MP, Gough W, Siewierski R. Anomalous climatic conditions during winter 2010-2011 and vulnerability of the traditional Inuit food system in Iqaluit, Nunavut. Polar Rec (Gr Brit). 2015;51(3):301-17.

21. Krawchenko T, Keefe J, Manuel P, Rapaport E. Coastal climate change, vulnerability and age friendly communities: linking planning for climate change to the age-friendly communities' agenda. J Rural Stud. 2016;44:5562. doi: 10.1016/j.jrurstud.2015.12.013.
22. Drolet JL, Sampson T. Addressing climate change from a social development approach: small cities and rural communities' adaptation and response to climate change in British Columbia, Canada. Int Soc Work. 2017;60(1): 61-73.

23. Medeiros AS, Wood P, Wesche SD, Bakaic M, Peters JF. Water security for northern peoples: review of threats to Arctic freshwater systems in Nunavut, Canada. Reg Environ Chang. 2017; 17(3):635-47.

24. Bakaic M, Medeiros AS. Vulnerability of northern water supply lakes to changing climate and demand [Internet]. Arct Sci. 2017;3(1):1-16. Available from: http://www.nrcresearchpress .com/doi/10.1139/as-2016-0029

25. Harper SL, Edge VL, Ford J, et al. Climate-sensitive health priorities in Nunatsiavut, Canada. BMC Public Health. 2015;15(1):605.

26. Bishop-Williams KE, Berke O, Pearl DL, Kelton DF. A spatial analysis of heat stress related emergency room visits in rural Southern Ontario during heat waves. BMC Emerg Med. 2015; 15(1):1-9. doi: 10.1186/s12873-015 $-0043-4$.

27. Cunsolo A, Shiwak I, Wood M. "You Need to Be a Well-Rounded Cultural Person": youth mentorship programs for cultural preservation, promotion, and sustainability in the Nunatsiavut Region of Labrador. In: Fondahl G, Wilson G, editors. Northern Sustainabilities: Understanding and Addressing Change in the Circumpolar World. Springer Polar Sciences. 2017:285-303.

28. Government of Manitoba. A made-inManitoba climate and green plan. Hearing from Manitobans [Internet]. Government of Manitoba; 2017. Available from: http://www.gov.mb.ca /asset_library/en/climatechange /climategreenplandiscussionpaper.pdf

29. Province of New Brunswick. Transitioning to a low-carbon economy: New Brunswick's climate change action plan. Fredericton (NB): Province of New Brunswick; 2016. Available from: https://www2.gnb.ca/content/dam /gnb/Departments/env/pdf/Climate -Climatiques/TransitioningToALow CarbonEconomy.pdf
30. Vasseur L, Thornbush M, Plante S. Gender-based experiences and perceptions after the 2010 winter storms in Atlantic Canada. Int J Environ Res Public Health. 2015;12(10):12518-29.

31. Public Health Agency of Canada. The Rural Think Tank 2005 - Understanding issues families face living in rural and remote communities [Internet]. Ottawa (ON): Public Health Agency of Canada; 2007. Available at: http://www.phac -aspc.gc.ca/hp-ps/dca-dea/publications /rtt-grr-2005/2-eng.php 